\title{
The Use of the Audio Pen in Enhancing Reading Skills among Preschool Children
}

\author{
Pramela Krish
}

\begin{abstract}
Having good reading skills has many advantages to the individual in both educational and wider social contexts throughout life. To be a proficient reader, one needs to master phonemic awareness, phonics, fluency, vocabulary and comprehension skills. The study aims to investigate the effectiveness of the use of the audio pen as an assistive technology in reading to develop reading fluency, comprehension and vocabulary skills among preschool children in a selected semi-urban preschool. Data was collected from the reading skills tests, and interviews. A total of 10 preschool children between five to six years of age were selected to use the audio pen as an intervention for a duration of eight weeks. The results from the tests showed that the majority of the children improved their reading fluency, comprehension and vocabulary skills. The results of the interviews showed that most of the participants had a positive perception and positive engagement in the use of the audio pen. These positive results suggest that an audio pen is a feasible and good intervention to be used along with traditional texts to enhance reading skills among preschool children.
\end{abstract}

Index Terms-Audio pen, comprehension, and vocabulary, fluency, preschool children, reading skills.

\section{INTRODUCTION}

The digital platform has created numerous opportunities to practice, teach, learn and create interesting and innovative methods for those interested in language and more so English language. The use of information and communication technology (ICT) can have positive effects on the learning and development of children. Currently, more and more interactive digital materials are being used to promote English oral literacy. With ICT becoming the key driver, learners are required to arm themselves with skills such as critical thinking, emotional intelligence, judgment, negotiation, cognitive flexibility as well as knowledge production and management [1].

Reading is a vital component in the development of a child's literacy and is also considered one of the most important academic abilities that establish the foundation for a child's success in school [2], [3]. Literacy development in a child is about learning sounds, words, and language. Literacy is the basis for a child's ability to read, write, communicate and socialize.

[4] defined the skill of reading as a complicated system that derives meaning from print. Such definitions recognize that the act of reading relies on both cognitive and social processes to derive meaning from print. This means, for

Manuscript received November 12, 2019; revised March 16, 2020.

Pramela Krish is with University Kebangsaan Malaysia, Malaysia (e-mail: pramela@ukm.edu.my). children to be good readers, they need to comprehend the meaning comprehensively from the print. Five skills that are necessary for proficient reading among children are phonemic awareness, phonics, fluency, vocabulary, and comprehension [5]. These skills can be separated into two main groups: word-level skills and broader text-level skills. Word level skills include phonemic awareness and phonics, while broader text-level skills include fluency, vocabulary, and comprehension.

According to [6] the fundamental and foundational associations required for gaining the success of later reading are provided by the reading skills acquired during the preschool stage. This explains the importance for children to have good skills in reading at an early age. In Malaysia, English is taught as a second language starting from the kindergarten level. For four to six-year-old children, English is taught under Preschool Education and the National Preschool Curriculum (NPC) and is implemented in all the public and private preschools as a requirement [7]. One of the major objectives of pre-school education is to enable children to master the basics of English. Besides, the NPC stipulated that all preschools with the national language as the medium of instruction must teach English at least two hours per week [8].

Some of the areas covered by NPC are the development of English language skills, creativity, physical ability, and problem-solving skill [9]. However, the Preschool Curriculum Implementation Study [7], Early Childhood Care and Education (ECCE) Policy Implementation Review [7] as well as the periodic School Inspectorate report indicate that many private preschools were still not adhering fully to this policy and this includes the development of English language skills [9]. Therefore, it becomes imperative for teachers to innovate the teaching methods to adopt technology to develop language skills. Technologies are considered essential tools in any level of the educational system. They can offer unlimited benefits to the students including the effective learning environment, confidence and learning autonomy [10].

Studies on technology to develop reading skills among children and studies on assisted technology on the use of the electronic book [11]-[13], web reading programs [14] and the use of self-modelling video [15] have shared positive results.

In recent years, several commercial audios or sometimes called as digital pen products with different features, such as [16], [17], Livescribe smartPen (http://www.livescribe.com), and LeapFrog Tag (http://www.leapfrog.com), have been developed. Several studies [18], [19] have revealed that audio pen technologies have already been successfully applied in designing digital pen and paper-based interactive 
learning environments in China and the United States.

Hence, promoting technology to enhance learning with such skills is important and must begin early in a child's life. This is especially so when it comes to reading among young learners. Technology in the form of the audio pen can be particularly suitable for younger children who cannot read yet and offers new opportunities that extend the traditional use of books.

A technology-based teaching and learning offers various interesting ways to make the learning process more fulfilling and meaningful. Therefore, the Theory of Technology-Supported Pedagogy forms the basis of the research to show how the use of technology especially an assistive technology like the audio pen promotes learning and assist in building reading skills.

\section{Assistive TECHNOLOGY IN READING}

Technology innovation and revolution have contributed to improving reading skills and positive learning behavior among children and adults. [20] state that technology improved students' ability to master reading skills and knowledge. Many studies have been conducted on technology as an assistive tool in language learning. A study conducted by [21] showed that technologies do support reading skills such as vocabulary and comprehension.

E-book or electronic book gained much attention among parents and teachers to develop children's reading skills. The features such as animations, sound effects, and advanced graphics attract children and make reading so much fun. [11] found the Israeli children who read the e-book exhibited significant progress in word meaning and word reading compared to the control group. Kindergarten children progressed in word reading more significantly than first-graders across treatment groups. Kindergarten children exhibited a good level of story comprehension, similar to first graders, although their story production was lower.

Some studies indicate that students still prefer or are used to paper-based reading and learning activities [22], [23]. These studies imply that screen technologies for English language learning may not be used effectively or accepted by all readers. This also means readers may not desire to replace completely the traditional paper-based reading mode with the digital reading mode [23]. Teachers were predominantly instructing and transmitting knowledge and were rarely observed to take responsive mediating approaches, despite proactive Chinese ICT policies which however lack specific curriculum guidance on pedagogy [24]. [25] believe that integrating interactive digital pen technologies with printed textbooks for assisting learning English has practical value. The findings also show that applying the audio pen to support a regular English language course in classrooms had significant positive effects in promoting the English language oral reading fluency, learning motivation, and learning satisfaction of junior school students.

A study by [26] on the effect of four different approaches to parent-child reading on young Chinese children's reading revealed that touch reading picture books are the most convenient and interesting for children. The findings also revealed an increased reading frequency and best reading effects among three experimental groups, has become popular among parents. The study concludes that the audio pen can be substituted for adults in accompanying reading to children to some point.

The audio pen is sometimes known as a digital pen, reading pen and also talking pen. The audio pen is an assistive technology that had been used in many children's reading programs. The audio pen will read the text out loud as it has a scanner that can read plain text into audio text. By decoding the printed pattern, the digital pen can track the pen's exact and absolute position on a printed paper. Moreover, each piece of the paper's pattern is unique; the digital pen can distinguish its location among the pages as well. According to [25] this kind of digital pen technology consequently offers flexibility, portability, and familiarity in enabling the users to exploit rich digital functions while keeping the natural interaction that is common in the traditional pen-and-paper interfaces.

[27] explain that with the audio pen literacy instruction, a context in which both traditional literacy skills and new literacies must be taught. It also revealed that by integrating the audio pen for reading lessons, student interest and attention to the tasks was sustained. An explorative study by [28] interviewed six children and their parents about how they are using digital audio pens and what role the devices play in influencing reading habits within the families. The audio pens are seen as apt for reading and language development, especially for children who get less support from their parents.

Looking at the positive role played by the audio pen in developing reading skills, it is timely that more studies on the effectiveness of audio pen in developing reading skills especially among children be carried out in Malaysia. Hence, the focus of this paper is on the use of the audio pen to enhance reading fluency, comprehension and vocabulary skills in the context of preschool children's reading skills in a selected kindergarten.

\section{DESIGN AND Methods}

This study employed a mixed method approach in data collection. The main research instrument in this study was the audio pen and the textbooks from Talking English set developed by Grolier Company. Talking English is a learning program that comes in a set of 20 textbooks with one audio pen. The books have 20 levels starting from level 1. This book comes with four units, each unit with five sections. The sections are Phonics time, What's new, Look! Look! Chat Box and Write Right! Each section explains the sounds of the alphabet, new words, the rule of word sounds, how to converse in English and writing practices.

For the purpose of this study, only four books were used (level 1 to level 4). The level of the books chosen was based on its difficulty via a pilot study that was carried out before the actual tests with the assistance of the class teacher. The presence of the class teacher throughout the study was important as she is a familiar figure to these young children.

The Reading fluency tests were adapted from [29]. The reading fluency tests were conducted to find out the number of correct words per minute (WCM) as well as the accuracy 
and the reading speed of the participants. In the test, the reading performance of a student is measured by asking the student to read a passage aloud for one minute, and the number of words read correctly was taken as the reading score. English educational experts have generally agreed that this one-minute reading test is sensitive, reliable and valid in measuring the students' oral reading fluency [15]. The comprehension and vocabulary tests were adapted from [11].

\section{A. Sample}

The sample for this study comprise children from a selected kindergarten. The level of reading skills of these children were described as average to weak by their class teacher. According to her, the children were not confident to read texts in English as the medium of instruction in the kindergarten was Malay. However, the more active children, aged between five and six years, participated in the study. Out of the ten children selected, five were boys and the rest were girls.

\section{B. Data Collection and Analysis}

The data was collected from test scores. For both comprehension and vocabulary Pre-tests and Post-tests, the words were selected from English Pasti Textbook while for Test 1 to Test 6 , the words were selected from Talking English Textbook Level 1 to Level 4. The number of words for the passage range from 76 to 153 words.

For the comprehension tests, the students were asked to answer seven to eight questions. The comprehensions tests consist of "yes and no" questions and choosing the right answer. For example, "Who has big hands and a big nose? Joe or Candy?" Again, only the correct answers were given marks and the scores were converted into percentages. For the vocabulary tests, the children needed to pair the words with the pictures. There were 10 words and 10 pictures in each test. In this test, a word would be said out loud and the children had to choose the answer by selecting the correct picture. To attract and sustain the children's attention, all pictures used were in color print.

Data was collected at three stages - Pre-intervention, Intervention and Post-Intervention. During the pre-intervention stage, the researchers explained to the participants how to use the audio pen via a training session. The participants were given 15 minutes to practise on how to use the audio pen, how to magnify the sound and how to place the pen correctly on the textbook. Next, the tests were also given as pre-tests and the scores were recorded as the baseline. The tests were administered individually on a one-on-one approach for each child. All the participants had sufficient practice to make sure that they understood the procedure. The reading fluency test was administered first, followed by a comprehension test and the last was the vocabulary test. The participants waited in the classroom until the researchers called them individually to do the tests. The tests had no cut-off time and the students took approximately $30-45$ minutes each to complete the tasks.

During the intervention stage, the participants worked individually with the textbooks that came along with the audio pen in six sessions. The participants completed the four levels of the textbooks. Each session lasted about 30 minutes.
The researcher decided on six sessions and during each session, the children were given the chance to repeat the readings three times. Three to four readings are an ideal number for supporting children's understanding of the story [30]. After the intervention session, the tests were given.

In the post-intervention stage, the procedure was the same as in the pre-test. The scores from the test were compared with the pre-test scores. At the end of the tests, the participants were interviewed on their experience about using the audio pen. The interviews questions focused on how they used the audio pens, what were their preferences in reading, and what difficulties/problems they faced when using these audio pens.

The test scores from the reading fluency tests, comprehension tests, and vocabulary tests were calculated into percentages for each participant. These test scores were used to compare between the scores obtained by the students before the intervention. The interview data was reported thematically to support the findings.

\section{FINDINGS}

This section will report the findings of the participants according to their reading fluency, comprehension and vocabulary scores.

\section{A. Reading Fluency}

Table I shows the reading fluency scores of the participants before and after the intervention.

TABLE I: READING FLUENCY SCORES

\begin{tabular}{ccccc}
\hline Participant & $\begin{array}{c}\text { Before } \\
\text { Intervention } \\
\text { (WCM) }\end{array}$ & $\begin{array}{c}\text { After } \\
\text { Intervention } \\
\text { (WCM) }\end{array}$ & $\begin{array}{c}\text { Average } \\
\text { score } \\
\text { (WCM) }\end{array}$ & $\begin{array}{c}\text { Score } \\
\text { improvement } \\
\text { (WCM) }\end{array}$ \\
\hline 1 & 2 & 11 & 8 & 9 \\
2 & 4 & 21 & 13.5 & 17 \\
3 & 4 & 14 & 12.9 & 10 \\
4 & 5 & 7 & 6.25 & 2 \\
5 & 4 & 6 & 4.4 & 2 \\
6 & 2 & 5 & 3 & 3 \\
7 & 10 & 10 & 7 & 0 \\
8 & 7 & 10 & 8 & 3 \\
$9 *$ & 65 & 85 & 76 & 20 \\
10 & 9 & 11 & 6 & 2 \\
\hline
\end{tabular}

According to [15], the oral reading fluency norms for students, aged six to seven years, is between $23 \mathrm{WCM}$ and 50 WCM. Participant 9 has 65 WCM which is the level of seven to eight-year-old reading fluency norm at the baseline. Participant 9 scored 85 WCM, and Participant 9 has an average 76 WCM (8-9 year reading fluency norm). This showed Participant 9 has significant improvements of 20 WCM and Participant 9 also had exceeded his age reading fluency norm after the use of the audio pen. A growing body of research acknowledges the importance of reading fluency as it is associated with proficient comprehension [31]. Being a fluent reader, Participant 9 would have a greater advantage in other reading skills like comprehension. Four out of ten students succeeded six to seven-year-old reading fluency norm in the reading fluency test. Nine out of 10 showed significant improvement from the intervention. Participant 1 only scored $2 \mathrm{WCM}$ at the beginning, which was very low for her age norm and at the end of the study she obtained 11 
WCM. Although the improvement was minimal, it showed the effectiveness of the use of the audio pen. As the majority of the participants showed improvements, the findings are consistent with the previous study by [18] on the effectiveness of the audio pen in developing reading fluency skill and the use of technology in developing reading fluency [32].

\section{B. Comprehension Scores}

Table II shows the comprehension scores of the participants before and after the intervention.

TABLE II: COMPREHENSION SCORES

\begin{tabular}{ccccc}
\hline Participant & $\begin{array}{c}\text { Before } \\
\text { Intervention } \\
(\boldsymbol{\%})\end{array}$ & $\begin{array}{c}\text { After } \\
\text { Invention } \\
(\boldsymbol{\%})\end{array}$ & $\begin{array}{c}\text { Average } \\
\text { score } \\
(\boldsymbol{\%})\end{array}$ & $\begin{array}{c}\text { Score } \\
\text { improvement } \\
(\boldsymbol{\%})\end{array}$ \\
\hline 1 & 71 & 75 & 87 & 4 \\
2 & 71 & 100 & 90.36 & 29 \\
3 & 71 & 100 & 92.12 & 29 \\
4 & 86 & 38 & 80.87 & -48 \\
5 & 71 & 75 & 65.5 & 4 \\
6 & 86 & 63 & 66 & -23 \\
7 & 71 & 86 & 95 & 15 \\
8 & 71 & 100 & 81 & 29 \\
9 & 65 & 85 & 93 & 14 \\
10 & 56 & 86 & 83 & 30 \\
\hline
\end{tabular}

As for comprehension skills, the study revealed that eight out of ten preschool children had improved the comprehension scores. The range of participants' average score is $65 \%$ to $93 \%$. This showed the effectiveness of the audio pen in improving the students' comprehension skills and it also reflects the findings of previous studies on the effects of technologies on comprehension skills [33]. The audio pen helped children to make the connection between the language knowledge and cognitive process as the audio pen produces different intonation of character's sounds in the reading session. Thus, the audio pen makes it easier for children to memorize the main component in the reading book such as characters and the storyline.

\section{Vocabulary Scores}

Table III shows the scores of the vocabulary skills of the participants before and after the intervention.

\begin{tabular}{ccccc}
\multicolumn{5}{c}{ TABLE III: VOCABULARY SCORES } \\
\hline Participant & $\begin{array}{c}\text { Before } \\
\text { Intervention }\end{array}$ & $\begin{array}{c}\text { After } \\
\text { Intervention }\end{array}$ & $\begin{array}{c}\text { Average } \\
\text { score }\end{array}$ & $\begin{array}{c}\text { Score } \\
\text { improvement }\end{array}$ \\
& $(\boldsymbol{\%})$ & $(\boldsymbol{\%})$ & $(\boldsymbol{\%})$ & $(\boldsymbol{\%})$ \\
\hline 1 & 40 & 20 & 54 & -20 \\
2 & 50 & 70 & 72.5 & 20 \\
3 & 70 & 60 & 65 & -10 \\
4 & 20 & 40 & 53.8 & 20 \\
5 & 30 & 70 & 55 & 50 \\
6 & 20 & 30 & 37.5 & 10 \\
7 & 50 & 90 & 52 & 40 \\
8 & 40 & 70 & 69 & 30 \\
$9 *$ & 80 & 90 & 72.5 & 10 \\
10 & 40 & 90 & 47.5 & 50
\end{tabular}

Based on the findings shown in Table III, eight out of 10 participants had improved the vocabulary test which means the majority of them showed improved scores. Typically, children's vocabulary knowledge has been evaluated in terms of breadth or words that they recognize. [34] defined vocabulary as the knowledge that encompasses all the words we must know to access our background knowledge, express our ideas and communicate effectively, and learn about new concepts. However, participants 1 and 3 did not show any improvement. This could also mean that they were weaker learners who would need more practice.

\section{DISCUSSION}

It can be concluded that the audio pen is effective in developing preschool children's reading skills. The improvement in scores from baseline to post-test in reading skills' tests indicates the effectiveness of the audio pen.

On the whole, throughout, the six sessions of intervention, nine out of ten participants scored high scores in the engagement elements. The elements are sustained behavioural involvement, positive emotional tones such as being cheerful, initiation of action when given the opportunity of intervention and exertion of effort and concentration. Findings showed positive engagement by the preschool children towards the use of the audio pen.

Interview findings with nine out of ten participants gave positive perception in terms of the use of the audio pen in reading. Nine out of ten participants expressed interest in the audio pen. They said the audio pen is easy to use, and it is a fun way of learning as it produces interesting sound effects and different intonations in the reading. The audio pen is easy to use as it only requires them touching the textbooks. It has an attractive design in terms of colour (yellow) and shape (cute face of caterpillar); the audio pen is fun to use it as it has sound effects. Participants also revealed that after using the audio pen, they think they have improved their English reading ability. Initially, most of the participants had low proficiency in English and were not confident to read in English. At the end of the reading sessions, the participants showed a high level of self-esteem and read louder than in the beginning. Lastly, nine out of ten participants would like to use the audio pen both at home and school every day. According to them, the use of the audio pen was fun and would increase their English reading skills.

The class teacher also observed that there was an improvement in terms of English reading and motivation to learn English among these children. She commented that English was only taught for one hour in a week and no reading session were conducted in English. The teachers also revealed that most of the students are not exposed to English reading materials in their homes. This may have resulted in low proficiency of English among preschool children and the low performance in the reading skills tests. Out of the 10 preschool children selected, P9 could have been wrongly selected as he showed a marked improvement. This child has good reading skills and using the audio pen simply shows more improvement. The teacher expressed her interest to use the audio pen to integrate with the traditional reading methods because she could see her students' performance improving. 


\section{CONCLUSION}

The study has shown the benefits of using the audio pen in improving children's reading fluency, comprehension, and vocabulary in a short duration. The participants' positive engagement and perception also proved the effectiveness of the audio pen as assistive technology. This further supports the Technology Supported Theory that serves as the foundation of this study

Based on the findings, it is evident that reading assistive technology aids in improving reading abilities. The findings demonstrate that the majority of the participants' test scores improved when compared to the earlier scores. Since the feature of the pen with a microphone enabled recognition of sound, we can deduce that the element of sound was a motivating factor for the participants to read better.

Studies on various types of assistive technologies in developing reading skills among preschool children should be continued. As in this study, the audio pen is quite similar to repeated reading. Both involve repeated exposure to the same text several times, through repeated reading. This repetition allows the child to achieve or view mastery. The benefits include gaining self-confidence and self-esteem, learning keywords and appropriate phrasing and building fluency. What is more interesting is the positive effects tells us that starting such technology integration early helps in instilling the 21 st-century skills like autonomy in a small scale as these children were able to practice independently and became active learners. Lastly, the findings cannot be transferred readily to most preschool children as this study worked with only ten preschool students. It is also hoped that similar research can be carried out in other types of preschool and in primary schools in the Malaysian context and countries with similar language requirements. The audio pen is relatively straightforward and feasible for teachers or parents to use with the preschool children daily at home or school. The method of using such technology can be easily coached to teachers and parents during a series of afterschool workshops where techniques could be learned and practised until fluency is reached.

\section{CONFLICT OF INTEREST}

There is no conflict of interest.

\section{ACKNOWLEDGEMENT}

This work was supported by Universiti Kebangsaan Malaysia Research Funds.

\section{REFERENCES}

[1] B. Xing and T. Marwala, Implications of the Fourth Industrial Age for Higher Education, The Thinker: For the Thought Leaders, vol. 73, pp 10-15, 2017.

[2] T. Horowitz-Kraus et al., "How to create a successful reader? Milestones in reading development from birth to adolescence: The contribution of language, cognition, and literacy to reading development," Acta Paediatrica, 2017.

[3] N. Carter, "What Instructional strategies are effective for increasing vocabulary for English language learners in a preschool classroom?" Masters Thesis, Hamline University Saint Paul, Minnesota, 2016.

[4] The National Institute for Literacy. What Content-Area Teachers Should Know About Adolescent Literacy, Washington, DC: The National Institute for Literacy, The National Institute for Child Health and Human Development (NICHD), The U.S. Department of Education's Office for Vocational and Adult Education, 2007.

[5] Report of the National Reading Panel, "Teaching children to read: on reading and its implications for reading instruction," Washington, DC: US (2000), Department of Health and Human Services, Public Health Service, National Institute of Health, National Institute of Child Health and Human Development, 2014.

[6] M. H. Alhumsi and A. Affendi, "The relationship between phonemic segmentation skill and EFL word recognition - A review of literature," International Journal of Linguistics, 2016, vol. 8, no. 2, pp. 31-46, 2016.

[7] Curriculum Development Division, Early Childhood Care and Education Policy Implementation Review, Malaysia: Ministry of Education Malaysia, 2007.

[8] Ministry of Education of Malaysia, Preschool Curriculum, Kuala Lumpur: Pusat Perkembangan Kurrikulum, 2001.

[9] N. S. Boon, "Governance of education related ECCE problems in Malaysia," International Journal of Children and Education Policy, 2010, vol. 14, no. 1, pp. 45-57, 2010.

[10] Z. Peivand and K. Pramela, "Enhancing EFL writing instruction through technology in Iran," Research on Humanities and Social Sciences, vol. 7, no. 18, pp. 75-83, 2017.

[11] O. Korat, "Reading electronic books as a support for vocabulary, story comprehension and word reading in kindergarten and first grade," Computers \& LeapFrog Tag, 2010.

[12] E. B. Miller and M. Warschauer, "Young children and e-reading: Research to date and questions for the future," Learning, Media and Technology, vol. 39, no. 3, pp. 283-305, 2014.

[13] L. Salmon, "Factors that affect emergent literacy development when engaging with electronic books," Early Childhood Education Journal, vol. 42, pp. 85-92, 2014.

[14] E. Wood et al., "Software to promote young children's growth in literacy: A comparison of online and offline formats," Early Childhood Education Journal, pp. 1-11, 2017.

[15] C. Robson, N. Blampied, and L. Walker, "Effects of feedforward video self-modeling on reading fluency and comprehension," Behaviour Change, vol. 32, no. 01, pp. 46-58, 2015.

[16] Qu-voice. [Online]. Available: http://www.myqu.com.tw

[17] Anoto, "Amy hutchison \& beth beschorner," Using the iPad as a Tool to Support Literacy Instruction, Technology, Pedagogy and Education, 2015, vol. 24, no. 4, pp. 407-422, 2015.

[18] C. M. Chen, C. C. Tan, and B. J. Lo, "Facilitating English-language learners' oral reading fluency with digital pen technology," Interactive Learning Environments, vol. 24, no. 1, pp. 96-118, 2016.

[19] A. Piper et al., "A pen-based toolkit for authoring collaborative language activities," in Companion Proc. ACM CSCW12 Conference on Computer-Supported Cooperative Work, vol. 23, no. 3, pp. 269-270, 2012.

[20] Biancarosa \& Griffiths, "Technology tools to support reading in the digital age," The Future of Children, 2012, vol. 22, no. 2, pp. 139-60.

[21] C. R. Greenwood et al., "Systematic replication of the effects of a supplementary, technology-assisted, storybook intervention for preschool children with weak vocabulary and comprehension skills," The Elementary School Journal, vol. 116, no. 4, pp. 574-599, 2016.

[22] K. Bromely, "Picture a world without pens, pencils and paper: The unanticipated future of reading and writing," Journal of College Reading and Learning, vol. 41, no. 1, pp. 96-108, 2010.

[23] W. D. Woody, D. B. Daniel, and C. A. Baker, "E-books or textbooks: Students prefer textbooks," Computers and Education, vol. 55, no. 3, pp. $945-948,2010$

[24] C. M. Dong and L. Newman, "Enacting pedagogy in ICT-enabled classrooms: Conversations with teachers in Shanghai," Technology, Pedagogy and Education, vol. 27, no. 4, pp. 499-511, 2018.

[25] C. C. Tan, C. M. Chen, and H. M. Lee, "Using a paper-based digital pen for supporting English courses in regular classrooms to improve reading fluency," International Journal of Humanities and Arts Computing, vol. 7, pp. 234-246, 2013.

[26] F. Yang, "The effect of four different approaches to parent-child reading on young chinese children's reading," International Journal of Education and Literacy Studies, vol. 4, no. 3, p. 47, 2016.

[27] A. Hutchison and B. Beschorner, "Using the iPad as a tool to support literacy instruction," Journal of Technology, Pedagogy and Education, vol. 24, no. 4, pp. 407-422, 2015.

[28] (2019). Marcel Rechlitz and Claudia Lampert Digital Audio Pens: Function and Use within the Family. [Online]. Available: https://www.hans-bredow-institut.de/en/projects/digital-audio-pens-to y-or-learning-tool 
[29] M. Clay, Running Records for Classroom Teachers, Auckland, New Zealand: Heinemann, 2000.

[30] M. T. Jong and A. G. Bus, "Quality of book-reading matters for emergent readers: An experiment with the same book in a regular or electronic format," Journal of Educational Psychology, vol. 94, no. 1, pp. 145-155, 2012.

[31] T. V. Rasinski et al., "Reading fluency and college readiness," Journal of Adolescent \& Adult Literacy, vol. 60, no. 4, pp. 453-460, 2014.

[32] G. Trainin et al., "Examining the impact of quickreads' technology and print formats on fluency, comprehension, and vocabulary development for elementary students," Journal of Research on Educational Effectiveness, vol. 9, pp. 93-116, 2016.

[33] L. C. Jones, "Using technology in language teaching and listening comprehension: Revisiting what teachers should know and do," IALLT Journal, 2016.
[34] J. D. Cooper et al., "Literacy: Helping students construct meaning," Cengage Learning.

Copyright $\odot 2020$ by the authors. This is an open access article distributed under the Creative Commons Attribution License which permits unrestricted use, distribution, and reproduction in any medium, provided the original work is properly cited (CC BY 4.0).

Pramela Krish is an associate professor at the Centre for Research in Language and Linguistics, Faculty of Social Sciences and Humanities, Universiti Kebangsaan Malaysia. She obtained her $\mathrm{PhD}$ in English language studies from Universiti Putra Malaysia in 2006. She has researched and published works on online learning and teacher professional development. Her research interests include technology-based language learning and the impact of new media in language learning and in society. 